\title{
The Contribution of Synaptic Inputs to Sustained Depolarizations in Reticulospinal Neurons
}

\author{
Myriam Antri, ${ }^{2 \star}$ Karine Fénelon, ${ }^{2 *}$ and Réjean Dubuc ${ }^{1,2}$ \\ ${ }^{1}$ Département de Kinanthropologie, Université du Québec à Montréal, Montréal, Québec, Canada H3C 3P8, and ²Groupe de Recherche sur le Système \\ Nerveux Central, Département de Physiologie, Université de Montréal, Montréal, Québec, Canada H3C 3J7
}

\begin{abstract}
Sensory stimulation elicits sustained depolarizations in lamprey reticulospinal (RS) cells for which intrinsic properties were shown to play a crucial role. The depolarizations last up to minutes, and we tested whether the intrinsic properties required the cooperation of synaptic inputs to maintain RS cells depolarized for such long periods of time. Ascending spinal inputs to RS cells were reversibly blocked by applying xylocaine over the rostral spinal cord segments. The duration of the sustained depolarizations was markedly reduced. The membrane potential oscillations in tune with locomotor activity that were present under control condition were also abolished. The contribution of excitatory glutamatergic inputs was then assessed by applying CNQX and AP-5 over one of two simultaneously recorded homologous RS cells on each side of the brainstem. The level of sensory-evoked depolarization decreased significantly in the cell exposed to the antagonists compared with the other RS cell monitored as a control. In contrast, local application of glycine only produced a transient membrane potential hyperpolarization with a marked reduction in the amplitude of membrane potential oscillations. Locally applied strychnine did not change the duration of the sustained depolarizations, suggesting that mechanisms other than glycinergic inhibition are involved in ending the sustained depolarizations in RS cells. It is concluded that excitatory glutamatergic inputs, including ascending spinal feedback, cooperate with intrinsic properties of RS cells to maintain the cells depolarized for prolonged periods, sustaining long bouts of escape swimming.
\end{abstract}

Key words: reticulospinal neurons; sensorimotor integration; sustained depolarization; glutamate; glycine; lamprey

\section{Introduction}

Neural activity depends on interactions between synaptic inputs and intrinsic membrane properties (Harris-Warrick and Marder, 1991; Marder, 1998; Steriade, 2001; Soto-Treviño et al., 2005; Marder and Goaillard, 2006). Understanding such interactions is particularly challenging in mammals because of the great complexity of their CNS and simpler models are needed. The CNS of lampreys provides excellent accessibility to cell networks as well as the possibility to identify detailed cellular mechanisms underlying behaviors (McClellan and Grillner, 1984; Di Prisco et al., 1997, 2000; Parker and Grillner, 1998; Grillner et al., 2001). In the spinal cord, synaptic inputs were shown to be essential to generate the basic locomotor pattern (Buchanan, 1999, 2001), and yet, postinhibitory rebound and bistable membrane properties con-

\footnotetext{
Received July 2, 2008; revised Nov. 20, 2008; accepted Dec. 20, 2008.

This work was supported by Individual and Group grants from the Canadian Institutes of Health Research (15129 and 15176 to R.D.), Natural Sciences and Engineering Research Council of Canada Grant 217435-01 (to R.D.), and the Groupe de Recherche sur le Système Nerveux Central from the Fonds de la Recherche en Santé du Québec (FRSQ) Grant 5249. M.A. received a Jasper Fellowship from the Université de Montréal. K.F. received a studentship from the FRSQ. We thank D. Veilleux for her assistance with the experiments, C. Valiquette for his expertise in computer programming, and F. Bernard for his help with the figures. We are also grateful to F. Auclair and J. Einum for critical review of this manuscript.

*M.A. and K.F. contributed equally to this work.

Correspondence should be addressed to Dr. Réjean Dubuc, Département de Kinanthropologie, Université du Québec à Montréal, Case Postale 8888, Succursale Centre-ville, Montréal, Québec, Canada H3C 3P8. E-mail: dubuc.rejean@uqam.ca.

D01:10.1523/JNEUROSCI.3073-08.2009

Copyright $\odot 2009$ Society for Neuroscience $\quad$ 0270-6474/09/291140-12\$15.00/0
}

tribute significantly (Wallén and Grillner, 1987; Matsushima et al., 1993; el Manira et al., 1994; Tegnér et al., 1997).

We previously demonstrated in the lamprey model that intrinsic membrane properties play a crucial role in the activation of brainstem reticulospinal (RS) neurons in response to sensory inputs (Di Prisco et al., 1997, 2000). At low stimulation strengths, synaptic responses are elicited in RS cells, the size of which increased linearly with the stimulation strength (Di Prisco et al., 1997) (see Fig. 3). Further increasing the stimulation intensity produced depolarizing plateaus that require the activation of NMDA receptors. We showed that once triggered, the depolarizing plateaus in RS cells were associated with the onset of locomotion in an in vitro semi-intact preparation, where the brainstem and rostral spinal cord were exposed with the tail left attached to freely swim behind. BAPTA injection into the recorded RS cell abolished the depolarizing plateaus. This indicated that intrinsic properties were involved and that they were calcium-dependent. We then showed that the sustained depolarizations were abolished by flufenamate suggesting that a calcium-activated nonselective cationic current $\left(I_{\mathrm{CAN}}\right)$ produced the depolarizing plateaus in RS cells. In other systems, depolarizing plateaus have been shown to be voltage-dependent (Kiehn, 1991). This was not seen for the sustained depolarizing plateaus we described in RS cells, despite the presence of calcium mediated intrinsic properties. Therefore, to avoid confusion, we will now use the term "sustained depolarizations" rather than "depolarizing plateaus."

In semi-intact preparations, the sustained depolarizations 


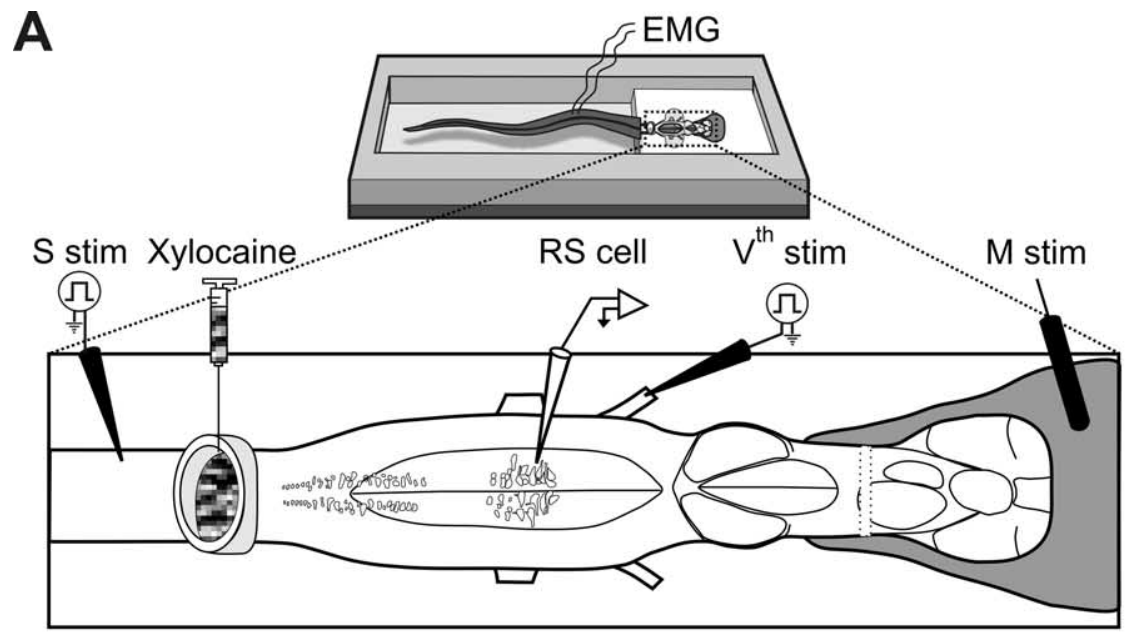

B1
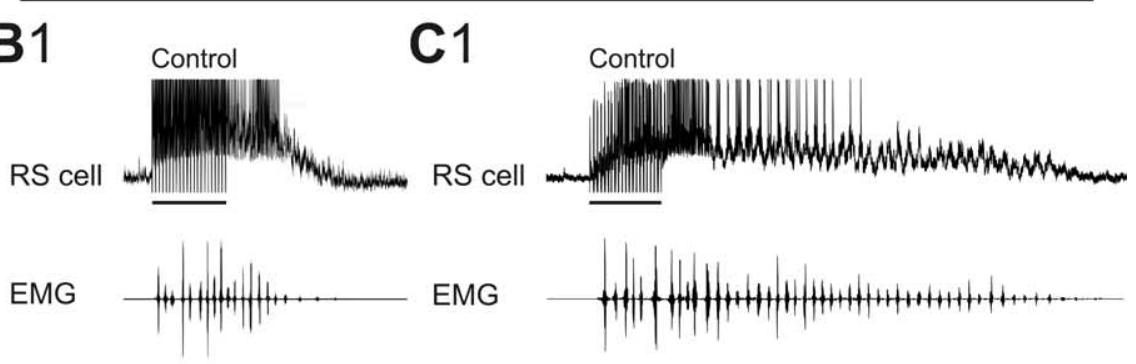

B2

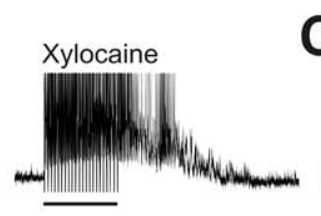

\section{C2}

RS cell

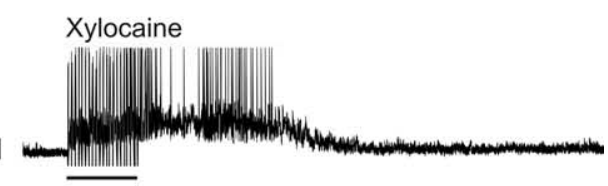

EMG

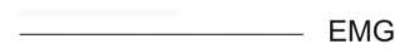

B3

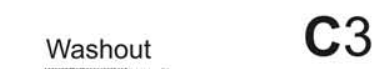

RS cell
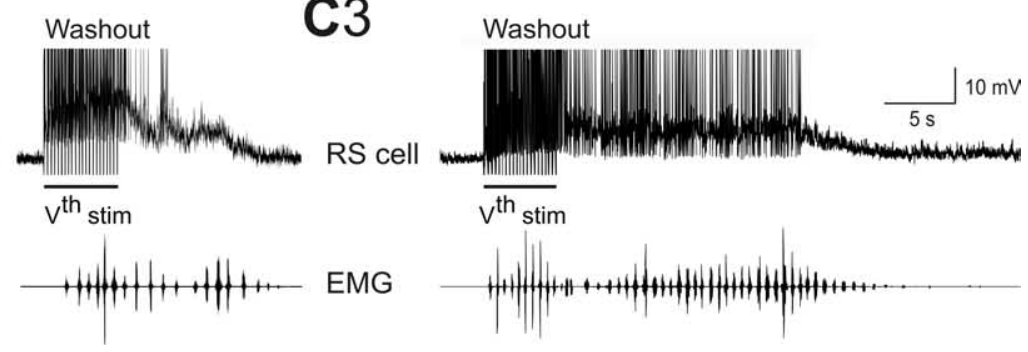

Figure 1. Effects of blocking spinal cord feedback with xylocaine on sensory-evoked sustained depolarizations. $A$, The experimental set-up. Stimulation of the ascending lateral columns ( $\mathrm{S}$ stim) was used to confirm that xylocaine blocked the connections between spinal cord and brainstem. Sustained depolarizations were intracellularly recorded from RS cells after mechanical pressure (M stim) applied to the skin covering the head, or electrical stimulation of the trigeminal nerve (Vth stim). Xylocaine was locally ejected in a circular bath tightly fitted on the rostralmost spinal segments. $\boldsymbol{B}, \boldsymbol{C}$, Sustained depolarizations of different durations (top) and EMG activity (bottom) recorded in two different preparations under control ( $B 1$ and $\mathbf{C}$ ), xylocaine ( $B$ 2 and $\mathbf{C 2}$ ) and after washout ( $\boldsymbol{B} 3$ and $\boldsymbol{C}$ ). The EMG activity was recorded at segmental level 30 . Note the absence of EMG activity under xylocaine (B2 and $\mathbf{C}$ ) and the recovery of EMG bursts after washout ( $B 3$ and $\mathbf{C}$ ).

could last for minutes. This raised the question as to whether intrinsic properties alone could provide such long-lasting sustained depolarizations in RS cells. We hypothesized that synaptic inputs could cooperate with the intrinsic properties to prolong the sustained depolarizations once elicited. This issue was addressed in this study. We now show that spinal cord inputs do contribute as well as excitatory glutamatergic inputs. Inhibitory inputs however did not shut off the sustained depolarization. Altogether our results indicate that synaptic inputs can modulate intrinsic properties to maintain the RS cells depolarized for long periods of time.

\section{Materials and Methods}

Semi-intact lamprey preparation. The experiments were performed on larval sea lampreys (Petromyzon marinus, $n=51$ ) collected from streams entering Lake Champlain. All surgical procedures conformed to the guidelines of the Canadian Council on Animal Care and were approved by the University Animal Care and Use Committees of the Université de Montréal and Université du Québec à Montréal. Before dissection, the animals were anesthetized with tricaine methanesulphonate (MS 222, $100 \mathrm{mg} / \mathrm{l}$, Sigma) and transferred to a solution of oxygenated (with $100 \% \mathrm{O}_{2}$ ), cold Ringer's, $\mathrm{pH} 7.4$, of the following composition (in $\mathrm{mm}$ ): $130 \mathrm{NaCl}$, $2.1 \mathrm{KCl}, 2.6 \mathrm{CaCl}_{2}, 1.8 \mathrm{MgCl}_{2}, 4$ HEPES, 4 dextrose and $1 \mathrm{NaHCO}_{3}$. The rostral part of the body down to the caudal gills was dissected extensively so that the skin, muscles and viscera were removed. The brain and the rostral spinal cord were exposed with the underlying cranium and notochord. The remaining caudal part of the body was left intact to freely swim in the recording chamber. A complete brain transection was performed rostral to the mesencephalon for decerebration purposes. In 7 experiments, the skin covering the dorsal head region was left attached.

This semi-intact preparation was then transferred to the recording chamber continuously perfused with cold oxygenated Ringer's $\left(8-10^{\circ} \mathrm{C}\right)$. The rostral, dissected end of the preparation was pinned down to a silicone elastomer (Sylgard, Paisley Products) at the bottom of the recording chamber, whereas the tail behind was completely free to swim in the deeper end of the chamber (Fig. 1A).

Recordings and stimulation. In all experiments, the recorded RS cells were located in the middle rhombencephalic reticular nuclei (MRRN) on both sides of the brain. The recorded cells were in all cases the giant Müller cells visually identifiable and bilaterally paired (Rovainen, 1967; Rovainen et al., 1973). Single and paired (bilaterally homologous cells) intracellular recordings of RS cells were performed. Neurons were impaled under visual inspection using sharp glass microelectrodes filled with $4 \mathrm{M}$ potassium acetate $(80-130 \mathrm{M} \Omega)$. Only RS cells with a stable resting membrane potential lower than $-65 \mathrm{mV}$ and having action potentials with amplitudes of $>70 \mathrm{mV}$ (truncated in the figures) were included in the data analysis. The intracellular recordings were made using an Axoclamp 2A amplifier in bridge mode (Axon Instruments) connected to a computer via a Digidata 1322 interface (Axon Instruments). The intracellular signals were digitized using Clampex 9.2 software (pCLAMP9 pack program; Axon Instruments). Off-line analysis was performed using Clampfit 9.2 software (Axon Instruments).

Different modes of sensory stimulation were applied to elicit sustained depolarizations in RS cells. Mechanical pressure was applied to the skin of the head using a fine probe (tip diameter of $0.5 \mathrm{~mm}$ ) kept at the same temperature as the bathing Ringer's solution. The probe was held above the preparation attached to a strain gauge connected to a computercontrolled step motor. The number of steps needed to reach the prepa- 
ration was calculated. Once the motor was activated, the probe moved down applying pressure to the skin after which it ascended back to its initial position. The number of steps was kept unchanged for all trials so that the stimulation (pressure) could be repeatedly applied at the same intensity for several trials, while monitoring the exact moment of the stimulation.

Electrical stimulation of the trigeminal nerve (Vth cranial nerve) was also used as a mean for eliciting sustained depolarizations in RS cells. Stimulation shocks of $1 \mathrm{~ms}(0.3-8 \mu \mathrm{A}$ at $2-50$ $\mathrm{Hz}$ ) were applied with a glass-coated tungsten microelectrode $(0.5-2 \mathrm{M} \Omega, 10-25 \mu \mathrm{m}$ tip; homemade) for periods lasting between $100 \mathrm{~ms}$ and $7 \mathrm{~s}$. The stimulation was delivered using a Grass S88 stimulator (Grass Instrument) connected to a stimulus isolation unit (SIU; Grass Instrument). Pinching the caudal dorsal fin of the body with fine forceps was also used to elicit the sustained depolarizations in RS cells. Each stimulation trial was followed by a resting period of at least $5 \mathrm{~min}$ to ensure that the recordings were made during steady conditions, with as little habituation of the responses as possible.

The swimming bouts were monitored by recording electromyographic (EMG) activity unilaterally or bilaterally. Pairs of Teflon-coated stainless steel wires (50 $\mu \mathrm{m}$ in diameter; California Fine Wire) were inserted in myotomes at the same rostro-caudal level on each side of the body (Fig. $1 \mathrm{~A}$ ). The EMG recordings were amplified $(1000 \times)$, filtered (bandwidth: 30 to 500 $\mathrm{Hz}$ ) and digitized at a sampling rate of $5 \mathrm{kHz}$.

Drug application. A small circular bath (2-3 $\mathrm{mm}$ in diameter) made of elastomer-type material (Reprosil, Vinyl Polysiloxane, Dentsply Caulk) was tightly fitted over the spinal cord, between the third and fourth segments. The small bath, carefully sealed with Vaseline, was first filled with a small drop of Ringer's solution colored with the inert dye Fast Green, a visual control to ensure that the bath was not leaking. Then, the small bath was filled with xylocaine $(0.01 \mathrm{mg} / \mathrm{ml}$, AstraZeneca) to reversibly block ascending spinal inputs to RS cells. The anesthetic, mixed with Fast Green, was ejected into the small bath through the needle of a $1 \mathrm{ml}$ syringe mounted on a micromanipulator. A 60-75 min washout period, where xylocaine was replaced with Ringer's, was allocated in some cases $(n=10)$ for spinal inputs to RS cells to recover. In 5 cases, sensory inputs ascending in the dorsal columns were blocked before xylocaine application. The dorsal columns on both sides were lesioned 1 or 2 spinal segments caudal to the level of the last pair of gill pores. Histological sections of the lesioned area were made to verify that the lesion included only the dorsal columns and not other spinal cord funiculi.

During locomotion, a mixture of glutamatergic antagonists, CNQX and AP-5 ( $1 \mathrm{~mm}, 2 \mathrm{~mm}$, respectively, $n=15 \mathrm{RS}$ cells), the inhibitory neurotransmitter glycine ( $1 \mathrm{mM}, n=19$ RS cells) or the glycine receptor antagonist strychnine ( $500 \mu \mathrm{M}, n=4$ RS cells) was locally ejected over one of two homologous RS cells recorded simultaneously on each side of the brainstem. The drugs were ejected on average $11.9 \pm 1.1 \mathrm{~s}$ after the sensory stimulation ended, not to interfere with the onset of the elicited sustained depolarizations. The responses of the homologous RS cell contralateral to the ejection served as a control. The ejections were made by applying positive pressure pulses $(10-200 \mathrm{~ms})$ through glass micropipettes using a Picospritzer (General Valve Corporation). As previously described by us and others (Paggett et al., 2004; Viana Di Prisco et al., 2005), care was taken to produce much localized actions of drugs. The drugs were ejected close to the tissue and the ejected solution was colored with Fast Green as a visual indicator for monitoring the extent of the diffusion. The outflow of the recording chamber was positioned near the ejection site to restrict the ejection to the immediate vicinity of the recorded RS cells. Ejections of Fast Green mixed with Ringer's did not produce any effect on RS cells (Brocard and Dubuc, 2003). In some cases, tetrodotoxin (TTX, $1 \mu \mathrm{M}$ ) was bath applied before and after bath perfusion of glycine $(100 \mu \mathrm{M})$.

All the above-mentioned drugs were purchased from Sigma, stored frozen in aliquots of stock solutions and diluted to the desired concentration in fresh Ringer's before use.

Data analysis. RS cells show sustained depolarizations with superimposed rhythmic membrane potential oscillations in response to sensory stimulation. The mean depolarization duration (in seconds) was measured in control, under xylocaine and, in 10 cases, after the washout period. The starting point for the measurement of the depolarization durations was when the values of the membrane potential $\left(V_{\mathrm{m}}\right)$ started to depolarize (above the resting level) right after the stimulation artifact. The end point was when the $V_{\mathrm{m}}$ values returned back to resting (or prestimulation) values. The effects of CNQX/AP-5 ejections were characterized by comparing the sustained depolarization durations of the control with that of the tested RS cells. The start and duration of the 
ejections (in seconds) were measured from the Picospritzer marker trace output. The effect of the drug mixture was also measured on the area of the EPSPs.

The effects of glycine ejections were characterized using several parameters: (1) the duration of the drug ejection (obtained from the Picospritzer marker trace output), (2) the maximum membrane potential hyperpolarization (in $\mathrm{mV}$ ), (3) the duration of the drug effect measured from the time elapsed between the beginning of the drug effect (i.e., intersection between a line fitted through the initial and sustained part of the depolarization and the first point where the $V_{\mathrm{m}}$ decreased bellow this fitted line) and the time when $V_{\mathrm{m}}$ returned to the depolarization level, (4) the latency (in seconds) between the start of the ejection (from the Picospritzer marker trace output) and the beginning of drug effect, (5) the time constant (tau) obtained by first, fitting an exponential curve between the beginning of the drug effect and the maximum hyperpolarization and then, taking the time (in ms) at which $63 \%$ of the maximum hyperpolarization was reached, (6) the return to baseline (subtracting the duration of the ejection from the duration of the effect).

The effect of the glycine receptor antagonist, strychnine, was also characterized. The duration (in seconds) of the sustained depolarizations of the control RS cells were measured and compared with that of the test RS cells.

The sustained depolarizations were accompanied by swimming in the semi-intact preparations. In all the experiments where membrane potential oscillations were clearly visible in RS cells during swimming under control condition, their amplitude was measured before and during drug ejections by subtracting a peak value from the following trough value. Because the ejections were done rapidly after the start of the sustained depolarizations, only 8 consecutive steady oscillations were measured in control and in the presence of the drugs, during a bout of locomotion.

The swimming cycle duration was determined by measuring the time lapse between the onsets of two consecutive EMG bursts on the same side using homemade software.

Statistical analyses were done using Origin software (Origin Lab Corporation). A Student's paired $t$ test was used to compare means between two groups. A one-way ANOVA, followed by a Tukey's test for post hoc analysis, was used to compare means between more than two groups. A Pearson's correlation analysis was also performed to test whether two groups were linearly correlated. A confidence level of $p<0.05$ was considered statistically significant.

\section{Results}

Sustained depolarizations elicited by sensory stimulation in RS cells varied considerably in duration from relatively short depolarizations to longer events that could even last more than a minute (3-110 s). Variability was observed within as well as between preparations. We previously showed that intrinsic properties played a crucial role in the sustained depolarizations (Di Prisco et al., 1997, 2000). We now examined whether synaptic inputs from the spinal cord (Dubuc and Grillner, 1989; Vinay and Grillner, 1993; Einum and Buchanan, 2004) as well as glutamatergic excitatory inputs in general could add to the intrinsic properties to prolong the depolarizations of RS cells.

\section{The contribution of spinal inputs to sustained depolarizations elicited in RS cells}

Action potential conduction was reversibly blocked in both ascending and descending spinal cord axons by locally applying the anesthetic xylocaine in a well constructed over the rostral spinal segments (Fig. 1A). The duration of the trigeminal-evoked sustained depolarization and locomotor activity were examined. In preliminary experiments, glass coated tungsten microelectrodes (0.5-2 $\mathrm{M} \Omega, 10-25 \mu \mathrm{m}$ tip; homemade) were used to microstimulate the ascending axons in the lateral spinal columns (Fig. $1, \mathrm{~S}$ stim) to confirm the blockade of spinal inputs by xylocaine. The rostro-caudal position of the stimulating microelectrode was
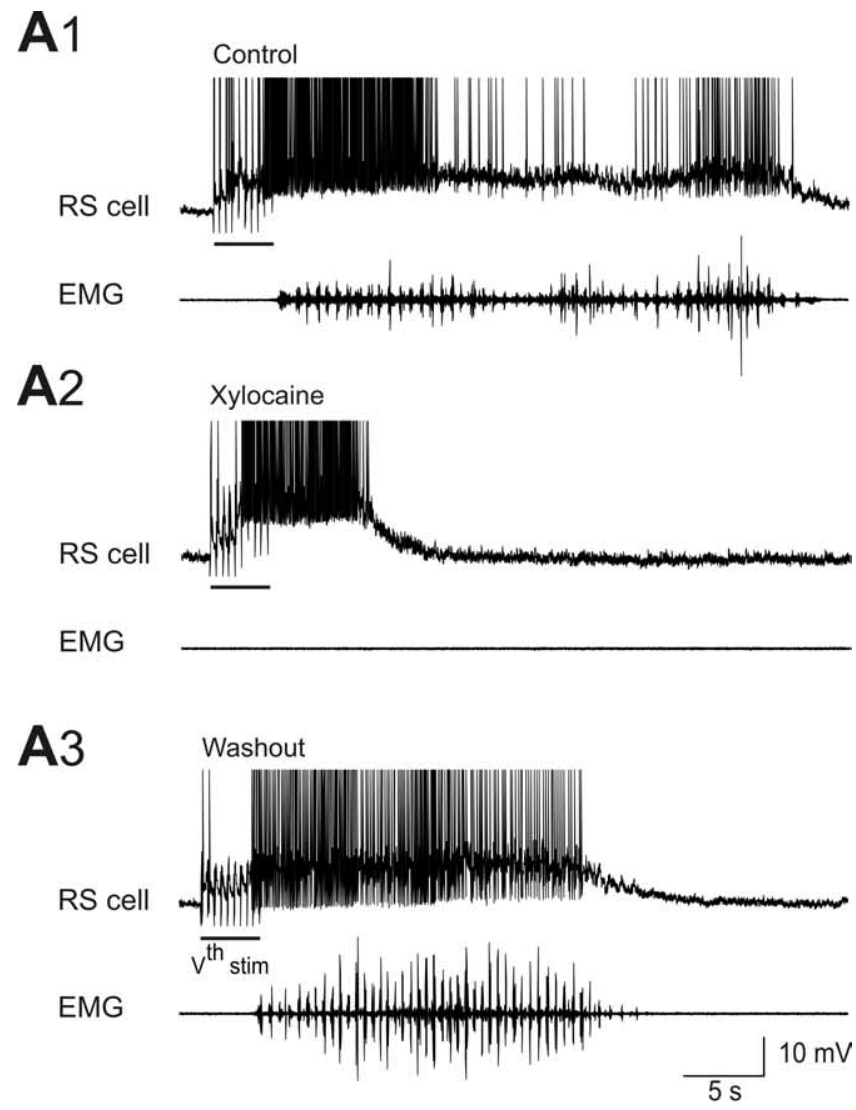

B

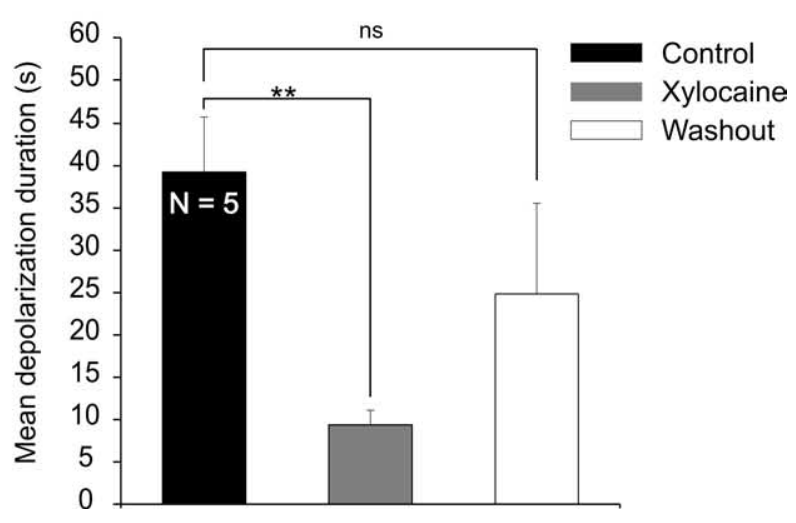

Figure 3. Effects of blocking ascending spinal inputs with xylocaine on sensory-evoked depolarizations in the absence of sensory feedback from the dorsal columns. A, After the bilateral lesion of the dorsal columns, sustained depolarizations were intracellularly recorded from RS cells in response to electrical stimulation of the trigeminal nerve (Vth stim). Sustained depolarizations (top) and EMG activity (bottom) recorded under control (A1), after xylocaine locally ejected in a circular bath fitted on the rostralmost spinal segments ( $\boldsymbol{A} \mathbf{2})$ and after washout $(\boldsymbol{A} \boldsymbol{3})$, in one preparation. Note that EMG bursts recorded at segmental level 30 were abolished under xylocaine $(\boldsymbol{A} 2, \mathrm{EMG})$ and recovered after washout $(\boldsymbol{A} \mathbf{3}, \mathrm{EMG}) . \boldsymbol{B}$, Histogram of the mean depolarization durations of five experiments under the three experimental conditions. ${ }^{* *} p<0.01$, $t$ test.

5-10 spinal segments caudal to the xylocaine bath. In all cases, the synaptic responses elicited by lateral column stimulation under control condition were abolished by xylocaine. Furthermore, during xylocaine, the trigeminal sensory stimulation failed to induce swimming indicating that the drug was efficiently blocking the connections between the brainstem and the spinal cord (Fig. $1 B 2, C 2$, EMG traces). In 20 of 22 recorded RS cells, the sustained 
depolarizations were still present (Fig. $1 B 2, C 2)$, but there was a significant decrease in the duration of the sustained depolarizations (Fig. $2 A, B$, xylocaine). In 10 of these cases, the RS cells were recorded long enough to obtain full or partial recovery (Fig. $2 A, B$, washout). After a washout period of 45-60 min, the sustained depolarizations recovered with a duration similar to that of control condition (Fig. 2B) (control $=28.8 \pm 4.5 \mathrm{~s}$; xylocaine $=$ $10.3 \pm 1.1 \mathrm{~s} ;$ washout $=31.5 \pm 7.2 \mathrm{~s} ; p<$ 0.01 for xylocaine, one-way ANOVA; $n=$ 20). Swimming activity also recovered (Fig. $1 \mathrm{~B} 2$ vs $1 B 3 ; 1 C 2$ vs $1 C 3$ EMG traces). In 2 of the 22 RS cells, xylocaine abolished the sustained depolarizations altogether (data not shown).

Interestingly, the effects of blocking ascending spinal inputs to RS cells varied depending on whether the sustained depolarizations were of short (Fig. 1B1) or of long duration (Fig. 1C1). Xylocaine significantly reduced the duration of the sustained depolarizations when the latter lasted $25 \mathrm{~s}$ or more (Fig. $2 \mathrm{~A}$ ). In the 9 neurons with depolarizations shorter than 25 s, xylocaine did not significantly reduce the duration (Fig. $2 C)(<25 \mathrm{~s}$; control $=$ $12.5 \pm 1.8 \mathrm{~s}$ vs xylocaine $=10.1 \pm 1.8 \mathrm{~s}$; $p>0.05$, $t$ test; $n=9$ ), whereas in the other 11 neurons in which the depolarizations lasted $>25 \mathrm{~s}$, there was a significant reduction after xylocaine (Fig. 2C) (>25 s; control $=43.4 \pm 4.9 \mathrm{~s}$ vs xylocaine $=8.9 \pm$ 1.7 s; $p<0.001, t$ test; $n=9$ ).

In 12 of 20 RS cells, membrane potential oscillations were clearly visible during swimming in control condition. Xylocaine abolished the oscillations in all cases. One such example is illustrated in Figure 1C2. In the remaining $8 \mathrm{RS}$ cells, the membrane potential oscillations were not large enough in control condition to allow quantification of their amplitude before and after xylocaine.

We then investigated the effects of reversibly blocking ascending inputs coming from the spinal cord in the absence of sensory feedback. In 5 experiments, the dorsal columns were bilaterally transected at the level of the rostralmost spinal segments. The duration of the trigeminal-evoked sustained depolarizations recorded in RS cells was then measured after the reversible blockade of the remaining ascending spinal inputs by locally applying xylocaine as described above. In control condition, long-lasting sustained depolarizations associated with locomotor activity were still induced in the absence of sensory feedback from the body (dorsal column lesion) (Fig. 3A1). Xylocaine application over the rostral spinal segments elicited a significant decrease in the duration of the sustained depolarizations (Fig. 3A2), as previously observed
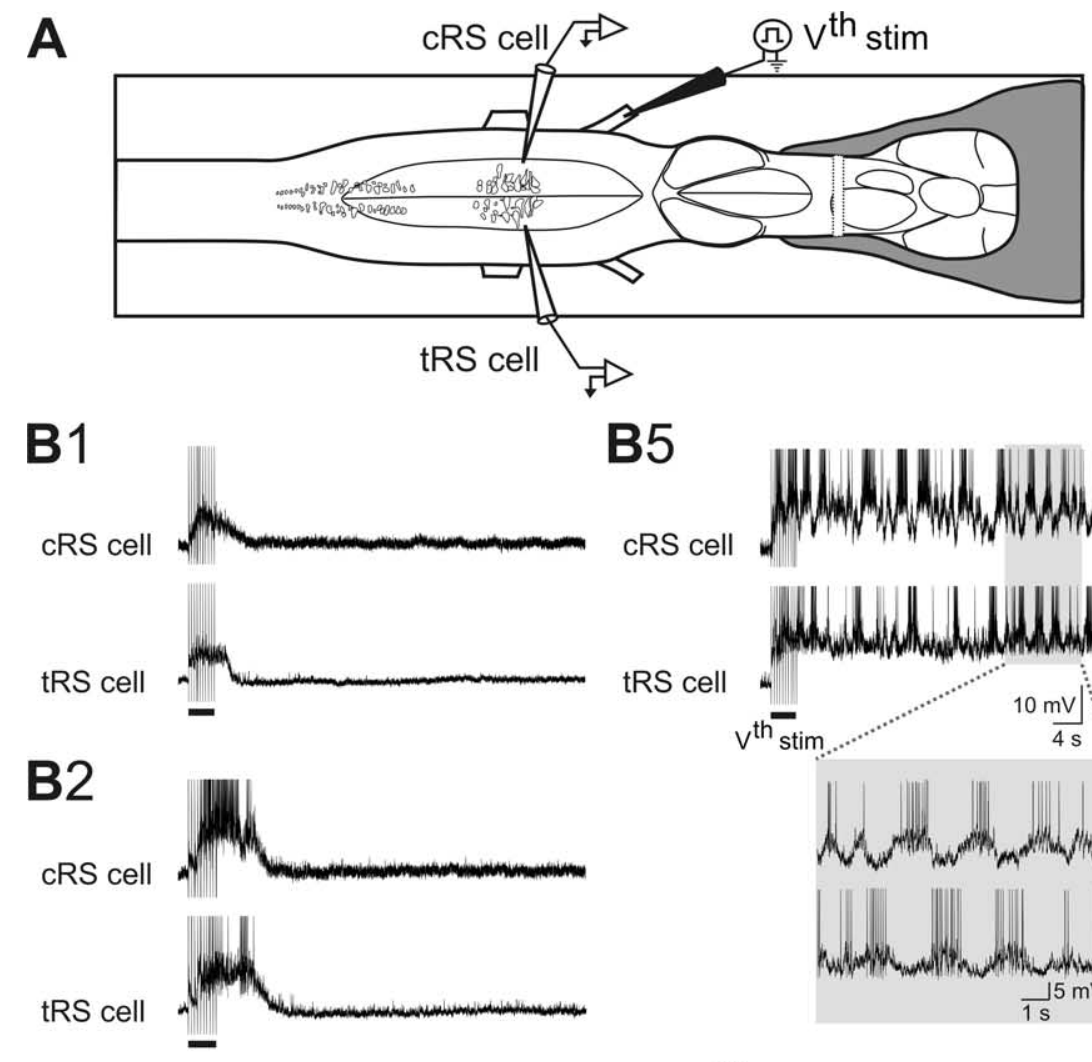

B5

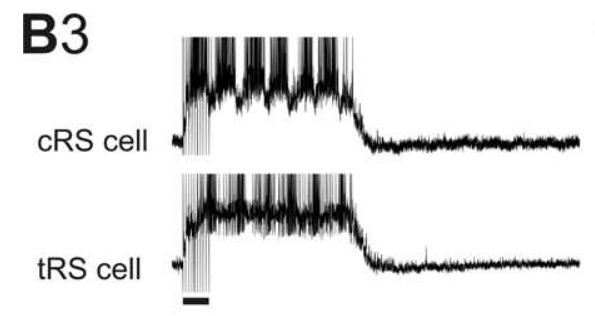

cRS cell

tRS cell
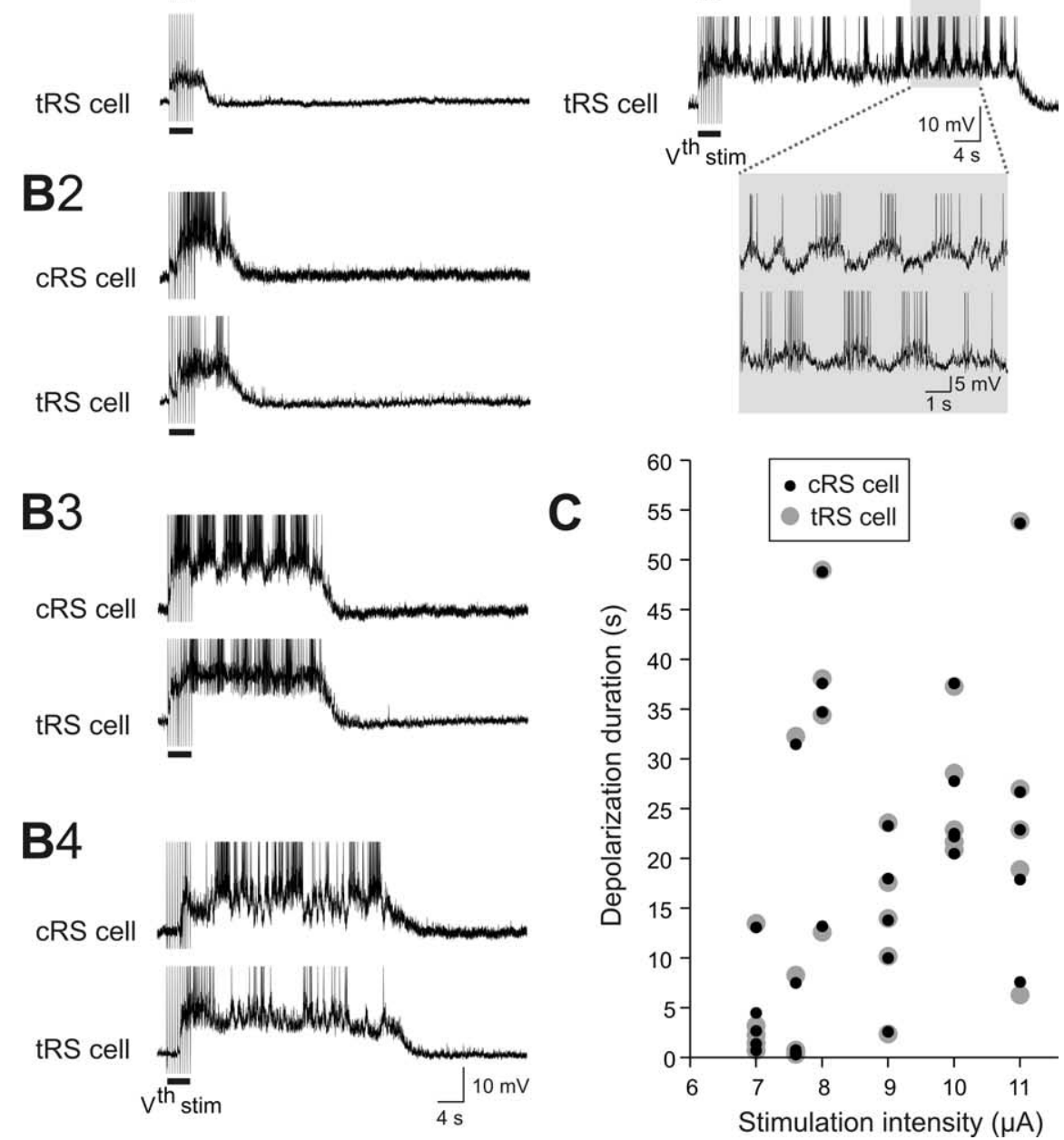

Figure 4. Sensory-evoked depolarizations in two simultaneously recorded homologous RS cells. $\boldsymbol{A}$, Drawing illustrating the experimental set-up. Paired intracellular recordings from two homologous RS cells located on either side of the brain were performed. One cell always served as the control RS cell (CRS cell) allowing drug ejections to be made over the tRS cell on the opposite side. $\boldsymbol{B} \mathbf{1}-\boldsymbol{B} 5$, Sustained depolarization recorded simultaneously in both cells at different trigeminal nerve stimulation intensities (7.0, 7.6, 11.0, 8.0 and 8.0 $\mu \mathrm{A}$, respectively). The depolarization varied similarly in the two $\mathrm{RS}$ cells from very short (B1, $3 \mathrm{~s})$, to much longer $(\boldsymbol{B} 5,50 \mathrm{~s})$. Note the alternating pattern of membrane potential oscillations observed in $\boldsymbol{B} \boldsymbol{5}$ (inset). $\boldsymbol{C}$, Plot of the stimulus-response relationship for the control (cRS cell, black circles) and the test (tRS cell, gray circles) RS cells illustrated in $\boldsymbol{B}$. The stimulation intensity varied from 7 to $11 \mu \mathrm{A}$ and the response durations from 3 to $55 \mathrm{~s}$.

in experiments where the dorsal columns were left intact. After a $60 \mathrm{~min}$ washout period, the reduction partially reverted back to control values (Fig. 3A3,B) (control $=39.3 \pm 6.5 \mathrm{~s}$, xylocaine $=$ $9.4 \pm 1.7$ s, washout $=24.8 \pm 10.7$ s, $p<0.01$, one-way ANOVA; $n=5)$.

Overall, these results suggest that the spinal cord inputs as- 
cending in the ventral and/or lateral columns contribute to maintaining RS cells depolarized for a longer period of time. Moreover, the rhythmic membrane potential oscillations seen in RS cells during locomotion would require spinal cord inputs.

\section{The effects of blocking excitatory glutamatergic inputs on sustained depolarizations}

The previous results stressed the contribution of spinal inputs to the sustained depolarizations in RS cells. The overall contribution of glutamatergic synaptic inputs (not only spinal) was then examined on semi-intact preparations. Homologous RS cells on either side of the brainstem were recorded intracellularly while a mixture of ionotropic glutamate receptor antagonists $(1 \mathrm{~mm}$ CNQX, 2 mM AP-5) was locally ejected over one of the recorded RS cells, the other cell serving as a control (Fig. $4 A$, test and control RS cells). First, we established that two homologous RS cells on either side exhibited sensory-evoked sustained depolarizations of identical durations (Fig. 4B1-B5). The response durations to a unilateral sensory stimulation were the same in the ipsilateral and contralateral RS cell populations (Fig. 4C). The membrane potential oscillations were however antiphasic in the two homologous RS cells recorded on either side (Fig. 4B5, inset). Because the ionotropic glutamate receptor antagonists were locally applied on one of the recorded RS cells [test RS (tRS) cell], it was necessary to determine the time course of the effects of the drugs. This was examined on the subthreshold synaptic responses elicited in RS cells $(n=4)$ by single shocks delivered to one trigeminal nerve at a low frequency $(0.1 \mathrm{~Hz}$ ) for $2 \mathrm{~min}$ (Fig. $5 A$ ). Preliminary data indicated that the effects were more prominent when the injections were made over the dendrites of RS cells, lateral to the soma rather than directly over the cell bodies (data not shown). Figure $5 B 1$ shows an example of the gradual decrease in EPSP area with time for one RS cell. The data for the four recorded cells are illustrated in Figure 5B2. The synaptic responses began to decrease 10-20 s after the ejection and the effect was about maximal after $60 \mathrm{~s}$. This indicated that the effects of the antagonists could be examined during the course of the sustained depolarizations. The effects were thus examined for 15 pairs of homologous RS cells recorded in 10 semi-intact preparations in which swimming was monitored through EMG recordings (Fig. 6A). The glutamate receptor antagonists CNQX and AP- 5 were ejected on average $8.9 \pm 1.2 \mathrm{~s}$ after the beginning of the sustained depolarization for a mean duration of $50.9 \pm 16.9 \mathrm{~s}$. As expected from the previous experiments (Fig. 5), the ejection did not produce an immediate effect. Instead, there was a gradual decrease in the membrane potential of the test RS cell compared with the control RS cell on the other side (Fig. 6C). Although the drug ejection ended before the end of the locomotor bout, the membrane potential of the test RS cell failed to return to the depolarization level comparable to that of the control RS cell on the nonejected side. Whereas the duration of the responses of two homologous cells was very similar and perfectly correlated under control condition (Fig. 6B,D1), the depolarization durations of the test RS cells were shorter (Fig. 6D2). Pooling the 15 pairs together showed a significant reduction of $32.2 \%$ in the depolarization duration of the test RS cells compared with the control homologous RS cells (cRS cells: mean depolarization duration $=100 \pm 12.2 \%$ of control; tRS cells: mean depolarization duration $=67.8 \pm 8.3 \%$ of control; $p<$ $0.01, t$ test; $n=15$ pairs). These results suggest that in addition to intrinsic properties, ionotropic glutamate receptor activa-
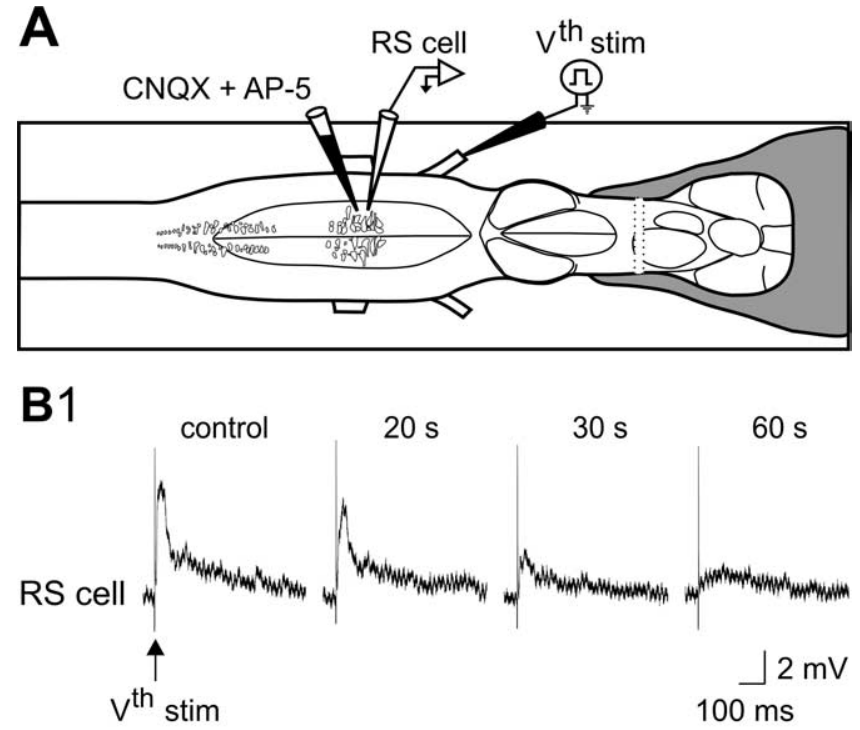

B2

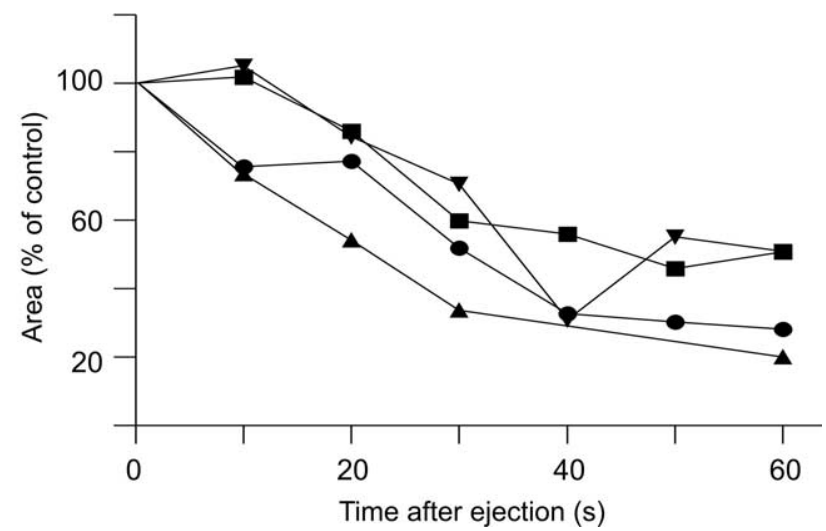

Figure 5. Effects of a local application of a mixture of CNQX (1 mm) and AP-5 (2 mm) on sensory-evoked subthreshold responses in a RS cell. $A$, Experimental set-up whereby glutamate receptor antagonists were locally pressure ejected over one $\mathrm{RS}$ cell. B1, A typical gradual reduction of the trigeminal-induced EPSPs is shown for one RS cell in control and after 20-, 30-, and 60-s exposure to the glutamate receptor antagonists. B2, Time course of EPSP areas (relative to control value) in four RS cells (different preparations) after exposure to the glutamate receptor antagonists. Traces in $\mathbf{B} \mathbf{1}$ are from the experiment represented by the inverted triangles.

tion contributes to maintaining RS cells depolarized for a long period of time.

The glutamate receptor antagonists CNQX and AP-5 also induced a gradual decrease in the amplitude of membrane potential oscillations related to the locomotor activity (Fig. 7). In 5 experiments, the mean oscillation amplitude decreased from $100 \pm$ $13.1 \%$ of control before ejection, to $67.3 \pm 9.7 \%$ of control $40 \mathrm{~s}$ after ejecting CNQX and AP5 ( $p<0.05, t$ test; $n=5$ ). However, there were no significant changes in EMG burst frequency or area after the local application of the antagonists over one RS cell on one side (Fig. 6C). For instance, the EMG burst frequency on the ejection side was $1.3 \pm 0.2 \mathrm{~Hz}$ in control versus $1.2 \pm 0.2 \mathrm{~Hz}$ after the drug ejection ( $40 \mathrm{~s}$ ). The values were the same on the opposite side. The mean area of the EMG bursts ipsilateral to the ejection was $837.9 \pm 275.5 \mathrm{mV} . \mathrm{s}$ in control versus $642.8 \pm 229.6 \mathrm{mV} . \mathrm{s}$ after ejection (40 s). On the contralateral side, mean area of the EMG bursts was $457.5 \pm 240.3 \mathrm{mV} . \mathrm{s}$ in control versus $318.6 \pm$ $143.4 \mathrm{mV}$.s after ejection ( $p>0.05$, paired $t$ test; $n=10 \mathrm{EMG}$ pairs). 
The effects of glycine receptor agonist and antagonist on sustained depolarizations

The above results suggest that intrinsic properties as well as excitatory synaptic transmission contribute to maintaining RS cells into a depolarized state. We investigated whether inhibitory amino acid transmission contributed to ending the sustained depolarizations. RS cells receive fast inhibitory glycinergic inputs from different sources such as the ascending dorsal and lateral columns in the spinal cord and from the trigeminal nerve (Dubuc et al., 1993a,b; Vinay et al., 1998a,b; Einum and Buchanan, 2004). Using the experimental paradigm described above, glycine (1 mM) was ejected on one of two homologous RS cells recorded simultaneously, during sustained depolarizations ( $n=19$ pairs) induced by sensory stimulation. Unlike the slow and gradual effects of the mixture of CNQX and AP-5, the effects of glycine were rapid (Fig. $8 A$ ). The ejection of the drug (durations ranging from 6.9-11.1 s; mean duration $=8.5 \pm 0.4 \mathrm{~s}$ ) produced a transient hyperpolarization ranging in amplitude from -5.36 to $-20.61 \mathrm{mV}$ with a mean value of $-12.4 \pm 0.8 \mathrm{mV}$. During the hyperpolarization, spiking activity ceased. Glycine acted very rapidly with a latency ranging from 0.04 to $0.45 \mathrm{~s}$ (mean $0.20 \pm 0.04 \mathrm{~s}$ ). The RS cell membrane potential hyperpolarized very quickly, as characterized by the very fast time constant (tau) ranging from 117.3 to 1726.7 $\mathrm{ms}($ mean $=594.2 \pm 100.0 \mathrm{~ms})$. The duration of the membrane hyperpolarization (ranging from 8.8 to $21.69 \mathrm{~s}$; mean $=$ $15.4 \pm 1.4 \mathrm{~s})$ was proportional to that of the glycine ejection ( $r=0.46 ; p=0.02$; $n=19$ ). In 56 trials (out of 66 trials), the ejection was stopped before the end of the sustained depolarization and the membrane potential promptly returned back to the pre-ejection level, similar to that of the control cell. The time required for the test cell to return to control depolarizing values ranged from 2.3 to $13.0 \mathrm{~s}$ with a mean of $7.1 \pm 1.3 \mathrm{~s}$ (Fig. $8 \mathrm{~A}$ ).

In 8 of the 19 pairs of RS cells, membrane potential oscillations were clearly visible under control condition. The amplitude of the oscillations was measured before and during the ejection of glycine (Fig. $8 B$ ). In 4 of 8 tested RS cells, the oscillations were no longer visible after glycine. In the other 4 cases, the oscillation amplitude decreased from $8.8 \pm 0.3 \mathrm{mV}$ to $2.2 \pm 0.2 \mathrm{mV}$ after glycine ejection $(p<$ $0.001, t$ test; $n=19)$. The frequency of the locomotor activity remained unchanged, most likely because the ejections were lo-
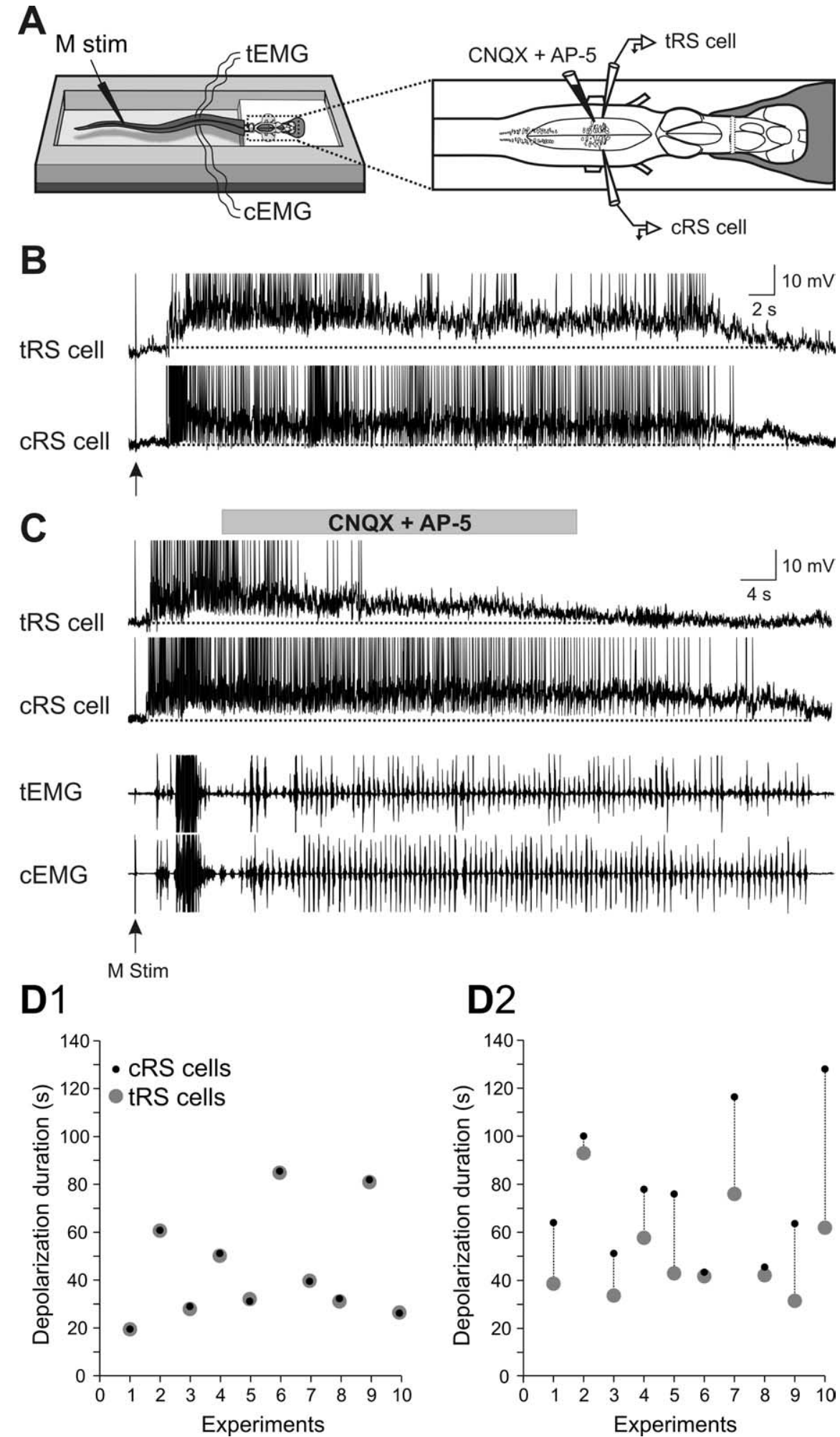

Figure 6. Effects of a local application of a mixture of CNQX (1 mM) and AP-5 (2 mM) over one of two homologous RS cells. $A$, The experimental set-up. $\boldsymbol{B}$, Paired intracellular recordings from two homologous RS cells on either side of the brainstem (control and test RS cells) showing sustained depolarizations induced by mechanical stimulation of the tail (arrow) under control condition. C, Local ejections of the glutamate receptor antagonists (gray horizontal bar) over the tRS cell. Note that the membrane potential depolarization decreased in the cell exposed to the glutamate receptor antagonists without affecting the contralateral control neuron (CRS cell). EMG activity (bottom traces) recorded at segmental level 30 from the control (CEMG) and test (tEMG) sides. Recordings in $\boldsymbol{B}$ and $\boldsymbol{C}$ are from the same neurons. D, Duration of sensory-evoked sustained dep olarizations for the control (cRS cell, black circles) and the test (tRS cell, gray circles) RS cells before (D1) and after local ejections of CNQX and AP-5 over the test RS cells (D2). Note that in the 10 pairs of simultaneously recorded homologous RS cells, the control RS cells and test RS cells display sustained depolarizations with similar durations under control condition (D1). After a local ejection of CNQX and AP-5, the sustained depolarizations in the test RS cells are in general of a shorter duration (D2). 

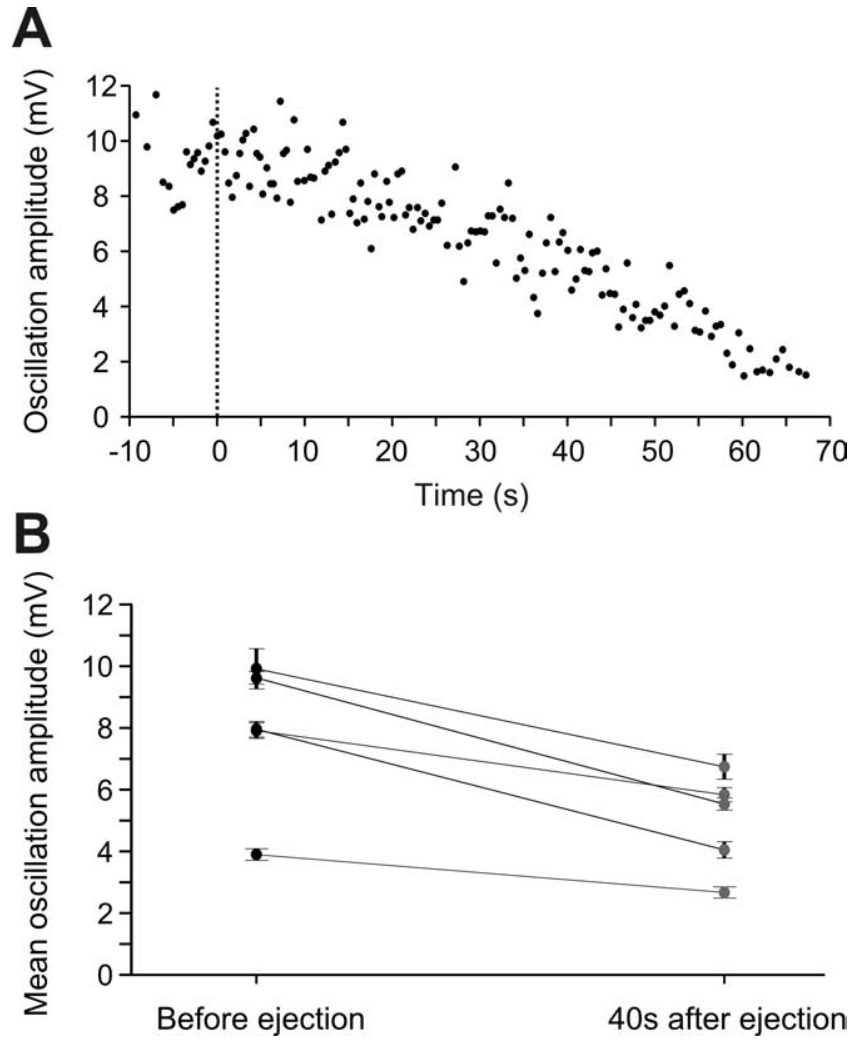

Figure 7. Effect of the glutamate receptor antagonists, CNQX and AP-5, on the amplitude of $\mathrm{RS}$ cell membrane potential oscillations during locomotion. $A$, Gradual decrease in the oscillation amplitude of one RS cell after the local application of CNQX (1 mM) and AP-5 (2 mM) at time $=0 \mathrm{~s}$ (dotted line). $\boldsymbol{B}$, Plot showing the mean amplitude ( \pm SEM) of a series of eight consecutive membrane potential oscillations measured in control and $40 \mathrm{~s}$ after the local ejections of CNQX and AP-5 for five RS cells.

calized over only a few RS cells out of the several hundreds in the nucleus. The effects of glycine were then examined on the current-voltage $(I-V)$ relationship in RS cells. Glycine was bathapplied $(100 \mu \mathrm{M})$ for $20-40 \mathrm{~min}$ in the presence of TTX $(1 \mu \mathrm{M})$. Current pulses ( $500 \mathrm{~ms}$; from -4 to $2.5 \mathrm{nA}$, average of 3 trials) were injected in the recorded RS cells $(n=2)$. Glycine produced a $14 \%$ decrease in the membrane input resistance of the recorded cells (from 13.1 to $11.2 \mathrm{M} \Omega$ ) (Fig. $8 C$ ).

As indicated above, RS cells receive glycinergic inputs from various sources, including the spinal cord. Glycinergic inputs could therefore provide an inhibitory signal at the end of the sustained depolarizations to provide a common repolarizing input to RS cells. To test this, the glycine receptor antagonist, strychnine $(500 \mu \mathrm{M})$, was locally applied over one of two homologous RS cells. In control condition as well as after strychnine ejection, both the control and the test cells had sustained depolarizations with similar durations (Fig. 9A, control; Fig. 9B, strychnine). In all experiments, strychnine ejection never produced significant change in the duration of sustained depolarizations ( $p>0.05, t$ test; $n=4$ pairs). Interestingly, however, strychnine ejection abolished the membrane potential oscillations and increased the firing frequency of the test cells (Fig. $9 A, B$, insets).

Overall, these results indicate that glycine transiently hyperpolarizes RS cells during the sustained depolarizations without terminating the latter, whereas the glycine receptor antagonist probably increases the firing frequency through a decrease in inhibitory inputs.

\section{Discussion}

We have previously shown that sensory inputs elicit sustained depolarizations in RS cells that are crucial for escape swimming in lampreys. Intrinsic membrane properties of the RS cells were shown to play a crucial role in these sustained depolarizations. We now show that blocking spinal inputs prevents the sustained depolarizations from lasting for very long periods of time and locally blocking AMPA and NMDA receptors of RS cells also reduces the amplitude and duration of the sustained depolarizations.

\section{Cooperation between intrinsic and synaptic properties}

In accord with the present results, we now propose that cooperation occurs between intrinsic and synaptic properties to temporally amplify the sustained depolarizations. The possible mechanisms by which this cooperation could occur is schematically illustrated in Figure 10. The "triggering sensory inputs" produces disynaptic excitation in RS cells via the activation of AMPA and NMDA receptors (hatched filling) followed by a sustained depolarization. The sustained depolarizations were shown to be prevented by chelating the intracellular calcium with BAPTA or adding flufenamate (Viana Di Prisco et al., 2000). We then concluded that intrinsic properties via the activation of an $I_{\text {CAN }}$ were essential ("intrinsic properties"; in gray). The present results suggest that the excitatory synaptic inputs allow for a temporal amplification of the sustained depolarizations. Thus, we propose that as the $I_{\text {CAN }}$ activation diminishes, excitatory glutamatergic synaptic inputs ("maintaining synaptic inputs"; in black), some of which coming from the spinal cord, would kick in to boost the $I_{\text {CAN }}$ activation. This would maintain the RS cells depolarized perhaps via additional calcium entry through NMDA receptors. Toward the end of the sustained depolarizations, both the intrinsic and the synaptic properties would gradually diminish. The RS cells would then repolarize and swimming end. It is unknown whether other active repolarization mechanisms such as common inhibitory inputs are involved.

\section{Contribution of spinal cord inputs}

RS cells are part of a spino-bulbo-spinal loop that plays a key role in controlling locomotion (Dubuc and Grillner, 1989; Vinay and Grillner, 1993). RS cells activate spinal interneurons and motoneurons (Rovainen, 1974; Buchanan, 1982; Buchanan and Cohen, 1982; Buchanan et al., 1987; Ohta and Grillner, 1989), and in turn, they receive inputs from the spinal cord locomotor networks (Dubuc and Grillner, 1989; Vinay and Grillner, 1993; Einum and Buchanan, 2004, 2005, 2006). Our results suggest that spinal inputs to RS cells are also involved to temporally amplify the sensory-evoked sustained depolarizations in RS cells. In the absence of spinal cord inputs, the RS cells were activated for a much shorter period of time $(<25 \mathrm{~s})$. Functionally, maintaining RS cells depolarized for long periods of time with additional temporal amplification may allow the lamprey escape response (McClellan and Grillner, 1983; McClellan, 1984) to be of sufficient duration for the animal to escape far away from the stimulus. Similar mechanisms may occur in other vertebrates including goldfish and zebrafish. These species display a vigorous escape reaction in response to sensory stimulation involving the reticulospinal system (Eaton et al., 1988, 2001; Fetcho and Faber, 1988; Gahtan et al., 2002).

The spinal neurons at the source of this temporal amplification could be the same than the ones previously described to provide a rhythmic monosynaptic input to reticulospinal cells 
during fictive locomotion (Einum and Buchanan, 2004, 2005; Buchanan and Einum, 2008). The ascending spinal neurons were also described anatomically and shown to be more numerous in the very rostral segments of the spinal cord (Vinay et al., 1998b). These projections ascend in the lateral or ventral columns.

The rhythmic membrane potential oscillations seen in RS cells during the swimming bouts were completely abolished by blocking the transmission between the spinal cord and the brainstem. RS cells have been shown to be rhythmically active during locomotion in several animal species, including mammals (Orlovsky, 1970a,b; Drew et al., 1986) and lampreys (Kasicki and Grillner, 1986; Dubuc and Grillner, 1989; Kasicki et al., 1989; Vinay and Grillner, 1992). Orlovsky proposed in the early 1970s that the rhythmic modulation in cat RS cells originated from the spinal locomotor networks (Orlovsky, 1970a). This remained a hypothesis for several years until the in vitro preparation of the lamprey brainstem/spinal cord was used to show that spinal cord inputs participated at least in part in the modulation of RS cells (Dubuc and Grillner, 1989). Results from the present study now indicate that spinal inputs are not only partly participating, but that they appear to be the sole contributors to the rhythmic modulation of RS cell activity during locomotion.

\section{Glutamatergic and glycinergic synaptic inputs}

The ejection of ionotropic glutamate receptor antagonists over one of two homologous RS cells induced a marked decrease in membrane oscillations and depolarization level in the cell receiving the drugs. The membrane potential progressively returned to resting levels despite the maintained depolarization in the control cell on the opposite side of the brainstem. Glutamatergic inputs thus likely contribute in maintaining RS cells into a depolarized state. A quantitative estimate of the synaptic inputs contribution cannot be provided. We cannot determine if all targeted glutamate receptors were blocked with the local ejections. Ejections over dendrites of RS cells, lateral to the soma, were more effective. Glutamate receptors were shown to be more densely distributed on the dendrites of spinal neurons in lampreys (Moore et al., 1995). Because the dendritic arborization of large RS cells within the MRRN is very extensive, the antagonists may require time to diffuse to the small ramifications of the RS cell dendrites deep in the tissue and we cannot assume that all ionotropic glutamate receptors were blocked.

It is tempting to propose that excitatory glutamatergic inputs coming from the spinal cord will be the most important in maintaining RS cells depolarized. However, we cannot rule out that other excitatory sources are involved during active locomotion. Several regions send excitatory glutamatergic projections to lamprey RS cells such as the mesencephalic locomotor region (Sirota et al., 2000) and the ventral thalamus in the diencephalon (El
Manira et al., 1997). Inputs from the periphery could also play a role Relay cells from trigeminal and vestibular inputs are also glutamatergic (Alford and Dubuc, 1993; Viana Di Prisco et al., 1995). It is noteworthy, however, that we found no difference in the duration of the sustained depolarizations before and after dorsal column lesion, indicating that somesthetic inputs from the body are unlikely to contribute much. To determine if the glutamatergic inputs are mostly originating from the spinal cord, it would have been interesting to study the effects of CNQX and AP-5 ejection under xylocaine condition. However, because of the long time needed for the antagonists to act (between 30 and $60 \mathrm{~s}$ ) and the short duration of the sustained depolarizations after xylocaine, this was not possible.

In contrast to blocking ionotropic glutamate receptors, glycine ejections onto the soma of a single RS cell caused an almost instantaneous, transient hyperpolarization of the RS cell membrane potential. Glycine did not end the sustained depolarization as the membrane potential of the test RS cell returned to a depolarized state similar to that observed in the control cell very shortly after the ejection. These results also support that the sustained depolarizations seen in RS cells are not voltage-dependent as the glycine-induced hyperpolarization failed to end the ongoing depolarizations. Moreover, the $I_{\text {CAN }}$ does not undergo voltage-dependant inactivation (Partridge et al., 1994; Zhang et 


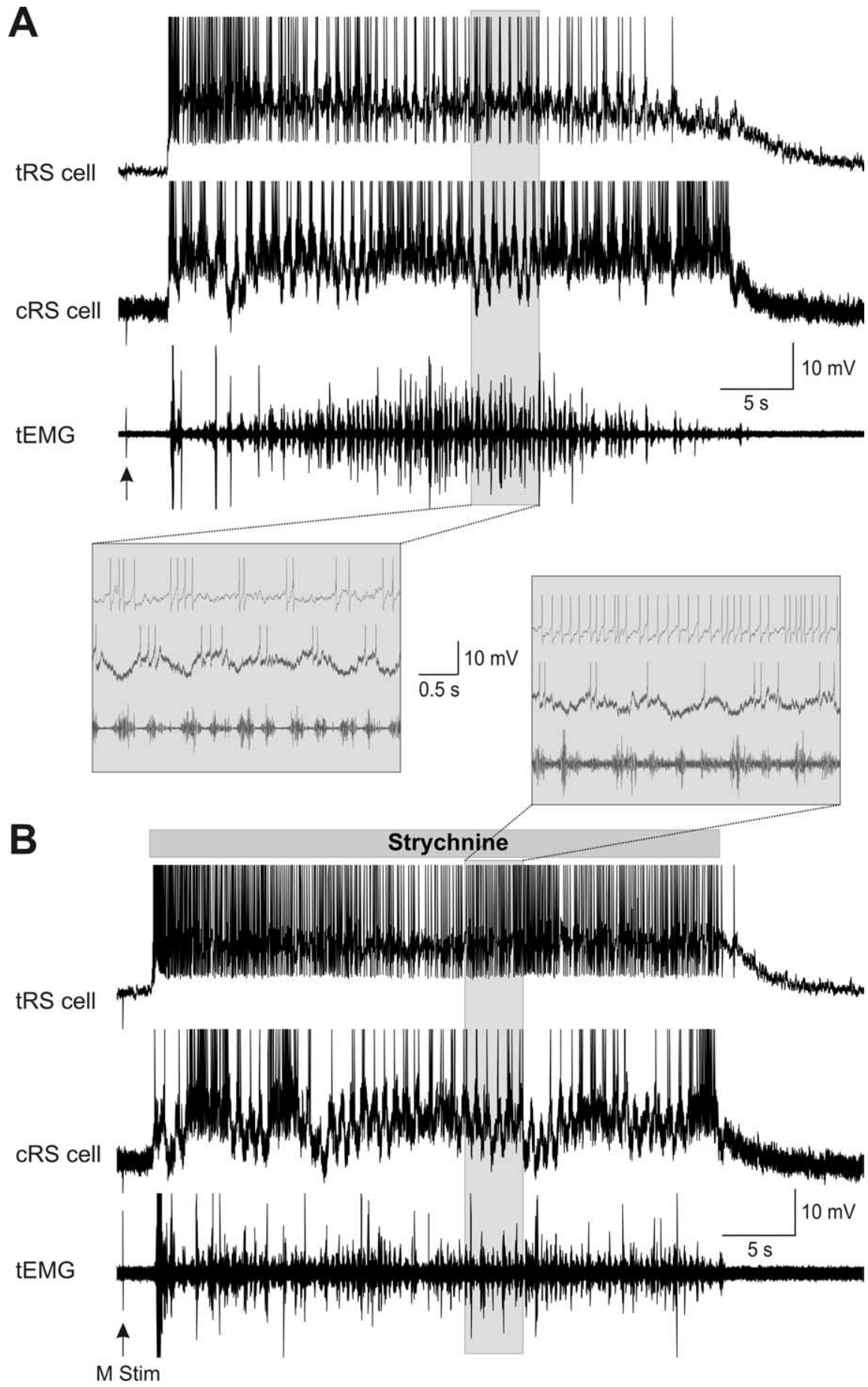

Figure 9. Effects of local ejections of strychnine (500 $\mu \mathrm{m}$ ) on sensory-evoked sustained depolarizations. $\boldsymbol{A}$, The control condition. Sustained depolarizations intracellularly recorded from two homologous RS cells, control (CRS) and test (tRS), in response to mechanical tail stimulation ( $M$ stim, arrow). Swimming activity was recorded ipsilateral to the tRS cell at segmental level 30 (tEMG). B, Effect of strychnine. The drug was locally applied over the test RS cell (tRS). Note that strychnine was applied from the beginning to the end of the sustained depolarization (gray horizontal bar). Insets, Parts of the traces (shaded areas) recorded under control or strychnine are shown at a faster time scale below $(\boldsymbol{A})$ or above $(\boldsymbol{B})$ the respective recordings. Traces in $\boldsymbol{A}$ and $\boldsymbol{B}$ are from the same pair of neurons. Note that strychnine neither prolonged the sustained depolarization of the tRS cell nor affected the cRS cell on the opposite side. Strychnine had also no effect on the swimming bout. However, strychnine abolished the membrane potential oscillations and increased the firing frequency of the tRS cell.

al., 1995). However, voltage-dependent long-lasting depolarizations were recorded in rat spinal and supraspinal neurons, involving L-type calcium channels opening and subsequent $I_{\text {CAN }}$ activation (Morisset and Nagy, 1999; Voisin and Nagy, 2001;
Baufreton et al., 2003; Zhu et al., 2005; Derjean et al., 2005; Lee and Tepper, 2007). GABA is also an important inhibitory neurotransmitter contained in several neuronal groups in the hindbrain of lampreys (Robertson et al., 2007). We performed preliminary experiments to test possible GABA contribution and found that it did not end the sustained depolarizations in 16 RS cells.

Whether the return to the previous depolarization level was due to intrinsic properties of the cell involving an $I_{\mathrm{CAN}}$ or due to change in synaptic drive cannot be determined. The very similar time course of the sustained depolarizations observed in two homologous RS cells suggests common synaptic inputs likely to play a crucial role in shutting down the sustained depolarizations. An excitatory drive could be relieved simultaneously for the entire population of the RS cells or a common synaptic inhibitory input could be activated. We have not found that inhibitory drive yet.

The oscillation amplitude was reduced by the application of glycine. The mechanisms by which this occurs remain to be established but a resistance shunt consequent to the drug-induced hyperpolarization is a possibility.

Finally, the locomotor cycle showed no change after glycine and CNQX/AP-5 local application onto a single RS cell. A complete block of all glutamatergic inputs projecting to the whole MRRN nucleus may be required to modify locomotor activity.

In conclusion, we provide evidence that excitatory synaptic inputs cooperate with intrinsic membrane properties to temporally amplify the sustained depolarizations in RS cells to elicit long bouts of escape swimming.

\section{References}

Alford S, Dubuc R (1993) Glutamate metabotropic receptor mediated depression of synaptic inputs to lamprey reticulospinal neurones. Brain Res 605:175-179.

Baufreton J, Garret M, Rivera A, de la Calle A, Gonon F, Dufy B, Bioulac B, Taupignon A (2003) $\mathrm{D}_{5}\left(\right.$ not $\mathrm{D}_{1}$ ) dopamine receptors potentiate burst-firing in neurons of the subthalamic nucleus by modulating an L-type calcium conductance. J Neurosci 23:816-825.

Brocard F, Dubuc R (2003) Differential contribution of reticulospinal cells to the control of locomotion induced by the mesencephalic locomotor region. J Neurophysiol 90:1714-1727.

Buchanan JT (1982) Identification of interneurons with contralateral, caudal axons in the lamprey spinal cord: synaptic interactions and morphology. J Neurophysiol 47:961-975.

Buchanan JT (1999) The roles of spinal interneurons and motoneurons in the lamprey locomotor network. Prog Brain Res 123:311-321.

Buchanan JT (2001) Contributions of identifiable neurons and neuron classes to lamprey vertebrate neurobiology. Prog Neurobiol 63:441-466. 
Buchanan JT, Cohen AH (1982) Activities of identified interneurons, motoneurons, and muscle fibers during fictive swimming in the lamprey and effects of reticulospinal and dorsal cell stimulation. J Neurophysiol 47:948-960.

Buchanan JT, Einum JF (2008) The spinobulbar system in lamprey. Brain Res Rev 57:37-45.

Buchanan JT, Brodin L, Dale N, Grillner S (1987) Reticulospinal neurones activate excitatory amino acid receptors. Brain Res 408:321-325.

Derjean D, Bertrand S, Nagy F, Shefchyk SJ (2005) Plateau potentials and membrane oscillations in parasympathetic preganglionic neurones and intermediolateral neurones in the rat lumbosacral spinal cord. J Physiol 563:583-596.

Di Prisco GV, Pearlstein E, Robitaille R, Dubuc R (1997) Role of sensory-evoked NMDA plateau potentials in the initiation of locomotion. Science 278:1122-1125.

Di Prisco GV, Pearlstein E, Le Ray D, Robitaille R, Dubuc R (2000) A cellular mechanism for the transformation of a sensory input into a motor command. J Neurosci 20:8169-8176.

Drew T, Dubuc R, Rossignol S (1986) Discharge patterns of reticulospinal and other reticular neurons in chronic, unrestrained cats walking on a treadmill. J Neurophysiol 55:375-401.

Dubuc R, Grillner S (1989) The role of spinal cord inputs in modulating the activity of reticulospinal neurons during fictive locomotion in the lamprey. Brain Res 483:196-200.

Dubuc R, Bongianni F, Ohta Y, Grillner S (1993a) Dorsal root and dorsal column mediated synaptic inputs to reticulospinal neurons in lampreys: involvement of glutamatergic, glycinergic, and GABAergic transmission. J Comp Neurol 327:251-259.

Dubuc R, Bongianni F, Ohta Y, Grillner S (1993b) Anatomical and physiological study of brainstem nuclei relaying dorsal column inputs in lampreys. J Comp Neurol 327:260-270.

Eaton RC, DiDomenico R, Nissanov J (1988) Flexible body dynamics of the goldfish C-start: implications for reticulospinal command mechanisms. J Neurosci 8:2758-2768.

Eaton RC, Lee RK, Foreman MB (2001) The Mauthner cell and other identified neurons of the brainstem escape network of fish. Prog Neurobiol 63:467-485.

Einum JF, Buchanan JT (2004) Reticulospinal neurons receive direct spinobulbar inputs during locomotor activity in lamprey. J Neurophysiol 92:1384-1390.

Einum JF, Buchanan JT (2005) Membrane potential oscillations in reticulospinal and spinobulbar neurons during locomotor activity. J Neurophysiol 94:273-281.

Einum JF, Buchanan JT (2006) Spinobulbar neurons in lamprey: cellular properties and synaptic interactions. J Neurophysiol 96:2042-2055.

el Manira A, Tegnér J, Grillner S (1994) Calcium-dependent potassium channels play a critical role for burst termination in the locomotor network in lamprey. J Neurophysiol 72:1852-1861.

El Manira A, Pombal MA, Grillner S (1997) Diencephalic projection to reticulospinal neurons involved in the initiation of locomotion in adult lampreys Lampetra fluviatilis. J Comp Neurol 389:603-616.

Fetcho JR, Faber DS (1988) Identification of motoneurons and interneurons in the spinal network for escapes initiated by the mauthner cell in goldfish. J Neurosci 8:4192-4213.

Gahtan E, Sankrithi N, Campos JB, O’Malley DM (2002) Evidence for a widespread brain stem escape network in larval zebrafish. J Neurophysiol 87:608-614.

Grillner S, Wallén P, Hill R, Cangiano L, El Manira A (2001) Ion channels of importance for the locomotor pattern generation in the lamprey brainstem-spinal cord. J Physiol 533:23-30.
Harris-Warrick RM, Marder E (1991) Modulation of neural networks for behavior. Annu Rev Neurosci 14:39-57.

Kasicki S, Grillner S (1986) Müller cells and other reticulospinal neurones are phasically active during fictive locomotion in the isolated nervous system of the lamprey. Neurosci Lett 69:239-243.

Kasicki S, Grillner S, Ohta Y, Dubuc R, Brodin L (1989) Phasic modulation of reticulospinal neurones during fictive locomotion and other types of spinal motor activity in lamprey. Brain Res 484:203-216.

Kiehn O (1991) Plateau potentials and active integration in the 'final common pathway' for motor behaviour. Trends Neurosci 14:68-73.

Lee CR, Tepper JM (2007) A calcium-activated nonselective cation conductance underlies the plateau potential in rat substantia nigra GABAergic neurons. J Neurosci 27:6531-6541.

Marder E (1998) From biophysics to models of network function. Annu Rev Neurosci 21:25-45.

Marder E, Goaillard JM (2006) Variability, compensation and homeostasis in neuron and network function. Nat Rev Neurosci 7:563-574.

Matsushima T, Tegnér J, Hill RH, Grillner S (1993) GABAB receptor activation causes a depression of low- and high-voltage-activated Ca2 + currents, postinhibitory rebound, and postspike afterhyperpolarization in lamprey neurons. J Neurophysiol 70:2606-2619.

McClellan AD (1984) Descending control and sensory gating of 'fictive' swimming and turning responses elicited in an in vitro preparation of the lamprey brainstem/spinal cord. Brain Res 302:151-162.

McClellan AD, Grillner S (1983) Initiation and sensory gating of 'fictive' swimming and withdrawal responses in an in vitro preparation of the lamprey spinal cord. Brain Res 269:237-250.

McClellan AD, Grillner S (1984) Activation of 'fictive swimming' by electrical microstimulation of brainstem locomotor regions in an in vitro preparation of the lamprey central nervous system. Brain Res 300:357-361.

Moore LE, Buchanan JT, Murphey CR (1995) Localization and interaction 
of N-methyl-D-aspartate and non-N-methyl-D-aspartate receptors of lamprey spinal neurons. Biophys J 68:96-103.

Morisset V, Nagy F (1999) Ionic basis for plateau potentials in deep dorsal horn neurons of the rat spinal cord. J Neurosci 19:7309-7316.

Ohta Y, Grillner S (1989) Monosynaptic excitatory amino acid transmission from the posterior rhombencephalic reticular nucleus to spinal neurons involved in the control of locomotion in lamprey. J Neurophysiol 62:1079-1089.

Orlovsky GN (1970a) Work of the reticulo-spinal neurones during locomotion. Biophysics USSR 15:761-771.

Orlovsky GN (1970b) Influence of the cerebellum on the reticulo-spinal neurones during locomotion. Biophysics USSR 15:928-936.

Paggett KC, Jackson AW, McClellan AD (2004) Organization of higherorder brain areas that initiate locomotor activity in larval lamprey. Neuroscience 125:25-33.

Parker D, Grillner S (1998) Cellular and synaptic modulation underlying substance P-mediated plasticity of the lamprey locomotor network. J Neurosci 18:8095-8110.

Partridge LD, Müller TH, Swandulla D (1994) Calcium-activated nonselective channels in the nervous system. Brain Res Brain Res Rev 19:319-325.

Robertson B, Auclair F, Ménard A, Grillner S, Dubuc R (2007) GABA distribution in lamprey is phylogenetically conserved. J Comp Neurol 503:47-63.

Rovainen CM (1967) Physiological and anatomical studies on large neurons of central nervous system of the sea lamprey (Petromyzon marinus). I. Müller and Mauthner cells. J Neurophysiol 30:1000-1023.

Rovainen CM (1974) Synaptic interactions of reticulospinal neurons and nerve cells in the spinal cord of the sea lamprey. J Comp Neurol 154:207-223.

Rovainen CM, Johnson PA, Roach EA, Mankovsky JA (1973) Projections of individual axons in lamprey spinal cord determined by tracings through serial sections. J Comp Neurol 149:193-202.

Sirota MG, Di Prisco GV, Dubuc R (2000) Stimulation of the mesencephalic locomotor region elicits controlled swimming in semi-intact lampreys. Eur J Neurosci 12:4081-4092.

Soto-Treviño C, Rabbah P, Marder E, Nadim F (2005) Computational model of electrically coupled, intrinsically distinct pacemaker neurons. J Neurophysiol 94:590-604.

Steriade M (2001) Impact of network activities on neuronal properties in corticothalamic systems. J Neurophysiol 86:1-39.

Tegnér J, Hellgren-Kotaleski J, Lansner A, Grillner S (1997) Low-voltageactivated calcium channels in the lamprey locomotor network: simulation and experiment. J Neurophysiol 77:1795-1812.

Viana Di Prisco G, Ohta Y, Bongianni F, Grillner S, Dubuc R (1995) Trigeminal inputs to reticulospinal neurones in lampreys are mediated by excitatory and inhibitory amino acids. Brain Res 695:76-80.

Viana Di Prisco G, Boutin T, Petropoulos D, Brocard F, Dubuc R (2005) The trigeminal sensory relay to reticulospinal neurones in lampreys. Neuroscience 131:535-546.

Vinay L, Grillner S (1992) Spino-bulbar neurons convey information to the brainstem about different phases of the locomotor cycle in the lamprey. Brain Res 582:134-138.

Vinay L, Grillner S (1993) The spino-reticulo-spinal loop can slow down the NMDA-activated spinal locomotor network in lamprey. Neuroreport 4:609-612.

Vinay L, Bongianni F, Ohta Y, Grillner S, Dubuc R (1998a) Spinal inputs from lateral columns to reticulospinal neurons in lampreys. Brain Res 808:279-293.

Vinay L, Bussières N, Shupliakov O, Dubuc R, Grillner S (1998b) Anatomical study of spinobulbar neurons in lampreys. J Comp Neurol 397:475-492.

Voisin DL, Nagy F (2001) Sustained L-type calcium currents in dissociated deep dorsal horn neurons of the rat: characteristics and modulation. Neuroscience 102:461-472.

Wallén P, Grillner S (1987) N-methyl-D-aspartate receptor-induced, inherent oscillatory activity in neurons active during fictive locomotion in the lamprey. J Neurosci 7:2745-2755.

Zhang B, Wootton JF, Harris-Warrick RM (1995) Calcium-dependent plateau potentials in a crab stomatogastric ganglion motor neuron. II. Calcium activated slow inward current. J Neurophysiol 74:1938-1946.

Zhu ZT, Munhall A, Shen KZ, Johnson SW (2005) NMDA enhances a depolarization-activated inward current in subthalamic neurons. Neuropharmacology 49:317-327. 